\title{
KOMODIFIKASI SASTRA CYBER WATTPAD PADA PENERBIT INDIE
}

\author{
Arif Budi Mawardi \\ General Manager Penerbit Sint Publishing \\ 0895374273027
}

\begin{abstract}
Wattpad is the site that gives possibility to the internet users to read or share literary works of short story, novel, and poetry. Wattpad was launched in 2006 by Allen Lau and Ivan Yuen. Nowdays, it is considered as an electronic literature with significant development. Most of the users of Wattpad are from USA; and then followed by the Great Britain and Canada. It comes to Asia then gets into Indonesia. In Indonesia, there are so many very popular electronic literary writers on Wattpad and they are not satisfied with their works which are only shared on cyber world. They decide to publish their works through publisher. Commodification of electronic literary work to the printed one becomes interesting study in literature, the most important thing is on the production process. This study explains (1) The existence of the electronic literary writers on Wattpad, and (2) The commodification of Wattpad electronic literature to printed literature through the indie publisher.
\end{abstract}

Key words: commodification, literature, wattpad, publishing.

\section{Pendahuluan}

Salah satu ciri khas manusia kapitalis adalah mengumpulkan uang sebanyakbanyaknya. Cara mengumpulkan uang sebanyak-banyaknya ini ditempuh dengan berbagai cara, salah satunya adalah merekayasa benda, pikiran, tujuan, atau budaya agar menarik di mata masyarakat sehingga akan menumbuhkan dorongan terhadap masyarakat untuk mendapatkan dan membelinya. Kegiatan merekayasa benda, pikiran, tujuan, atau budaya ini disebut dengan komodifikasi, sebagai kegiatan memodifikasi sesuatu agar menjadi barang komoditas yang dapat menghasilkan uang.

Seperti yang telah kita ketahui, karya sastra kini telah merambah di berbagai wahana. Wahana yang dinilai paling mutakhir adalah wahana elektronik yang melibatkan jaringan internet dan dapat mencakup masyarakat luas. Dalam hal ini karya sastra yang menggunakan wahana demikian disebut dengan sastra cyber. Sastra cyber akrab di masyarakat postmodern karena memenuhi segala aspek yang menjadi ciri khas masyarakat postmodern. Salah satu sastra cyber yang cukup lama bertahan adalah Wattpad, sebagai layanan situs yang memungkinkan pengguna internet untuk membaca atau mengirimkan karya sastra dalam bentuk cerita pendek, novel, puisi, atau karya sastra lain.

Wattpad diluncurkan pada tahun 2006 oleh Allen Lau dan Ivan Yuen. Wattpad dianggap sebagai salah satu bentuk sastra cyber yang mengalami perkembangan cukup pesat dewasa ini. Sebagian besar pengguna Wattpad mulanya berasal dari Amerika Serikat, yang kemudian diikuti oleh Britania Raya, Kanada, dan kemudian masuk ke Asia, kemudian sampai di Indonesia. Di Indonesia banyak penulis sastra bermunculan di dunia maya yang kemudian menunjukkan eksistensinya melalui situs Wattpad. Banyak penulis merasa nyaman dengan fitur dan layanan Wattpad karena tiap pengguna bebas melakukan editing dan penambahan pada karyanya. Selain itu, penulis di akun Wattpad juga dapat berkomunikasi langsung dengan pembaca melalui kolom komentar yang telah disediakan oleh pengelola situs.

Namun, hal yang menarik yaitu beberapa penulis yang populer di Wattpad merasa tidak cukup puas dengan karya cyber-nya dan ingin melanjutkan karyanya ke dalam bentuk sastra cetak. Komodifikasi 
sastra cyber ke sastra cetak ini menjadi kajian menarik dalam penelitian sastra, terutama penelitian sastra produksi.

Artikel ini bertujuan, pertama, untuk memberikan wawasan baru kepada pelaku sastra tentang perkembangan sastra cyber, komodifikasi, dan transformasinya ke sastra cetak, dan kedua, memberikan gambaran lebih luas mengenai sastra produksi dalam penerbit indie dan peranannya dalam perkembangan sastra kontemporer.

Artikel dengan pendekatan kualitatif ini hendak memahami secara mendalam tentang munculnya Wattpad sebagai wahana baru yang menarik pelaku sastra kontemporer. Penulis karya sastra Wattpad menerbitkan karyanya melalui penerbit indie guna kepentingan komoditas menjadi fenomena menarik untuk dibahas karena dari fenomena ini karya-karya baru bermunculan.

\section{Wattpad, Penulis Sastra Cyber, Komodifikasi Sastra Cyber \\ 2. 1. Wattpad \& Author Wattpad}

Wattpad merupakan situs online yang menyediakan fitur khusus bagi pemilik akun untuk meng-upload karyanya secara berkala. Karena diunggah secara berkala, maka karya sastra yang ada dalam Wattpad merupakan karya berseri. Jika dalam bentuk novel, maka karya tersebut biasanya akan diupload per bab (chapter) sehingga akan berkesinambungan dari bab awal hingga akhir. Selama proses penulisan tersebut, author (pemilik akun/pengarang) akan dapat berinteraksi langsung dengan follower (pengikut/pembaca) yang lebih akrab disebut reader (pembaca). Author dan reader dapat berinteraksi di kolom komentar. Bukan hanya memberikan komentar, follower atau reader bahkan dapat memberikan masukan, kritikan, hinaan, bahkan hujatan. Seolah-olah telah menjadi kesepakatan yang biasa dan wajar, segala hal yang disampaikan oleh reader bahkan dapat memengaruhi jalan cerita, menjadi pertimbangan author untuk melanjutkan, mengubah, atau bahkan menghentikan cerita.
Selain dipengarui oleh reaksi reader di kolom komentar, author seringkali menentukan cast (pemeran bagi tokoh dalam cerita). Foto cast dicantumkan dalam tubuh story (cerita). Cast biasanya diambil dari public figure (tokoh masyarakat) yang ada di dunia nyata. Berkaitan dengan cast, reader juga akan berkomentar tentang menarik tidaknya, mewakili cerita atau tidak.

Rata-rata, author yang ada di Wattpad adalah penulis pemula. Bahkan kebanyakan dari mereka mengenal dunia tulis-menulis pertama kali dari Wattpad dan bukan media lain, terlebih memelajari sastra di dunia nyata. Karenanya, tak jarang author atau penulis tak mengerti apa sesungguhnya karya fiksi, terlebih prosa. Mereka juga tak memahami apa sesungguhnya istilah-istilah yang ada dalam dunia sastra. Menariknya, dengan pemahaman yang minim tersebut justru memunculkan berbagai istilah baru yang mungkin tak diketahui oleh ahli sastra sekalipun. Istilah-istilah tersebut antar lain "blurd" yang seringkali disebut sinopsis, "cast" yang mereka gunakan untuk menyebut tokoh, serta pemahaman tentang point of view yang berbeda dengan pemahaman pada teori sastra. Mereka tak bisa memahami istilah-istilah pada prosa seperti plot, setting, tokoh (character), penokohan (characterization), dan lain sebagainya dengan baik. Mereka seolah-olah meraba, memahami, dan mengaplikasikan kemampuan mereka dengan pengetahuan yang mereka peroleh berdasarkan pengalaman membaca dan menulis di Wattpad. Bagi mereka dunia tulis-menulis dan kesusastraan di luar Wattpad tidaklah penting dan tidaklah benar. Dari sini munculah sikap fanatik terhadap karyanya.

Ketenaran akan eksistensi author Wattpad tergantung pada banyak tidaknya follower yang mereka punyai, ramai tidaknya komentar yang mereka dapatkan, dan seberapa banyak like yang mereka dapat. Situs Wattpad juga menyediakan fitur penghitung komentar, follower, dan bintang otomatis pada masing-masing akun. Wattpad juga dapat memberikan peringkat 
pada cerita yang mendapat komentar, follower, dan bintang terbanyak.

Ketenaran yang didapat oleh author kemudian memantik semangatnya untuk meningkatkan eksistensinya, yaitu dengan menerbitkan tulisannya dalam bentuk buku ber-ISBN yang bisa dijual dalam bentuk cetak, membuat video, merchandise, hingga sosial media yang dimainkan oleh roleplay cerita mereka. Kebanyakan penulis Wattpad memilik penerbit indie untuk menerbitkan karya mereka dengan berbagai pertimbangan. Saat ini, ditemui lebih dari 500 penulis Wattpad yang menerbitkan tulisannya melalui penerbit indie.

\section{2. Eksistensi Author Sastra Cyber pada situs Wattpad}

Ketenaran akan eksistensi author Wattpad tergantung pada banyak tidaknya follower yang mereka punyai, ramai tidaknya komentar yang mereka dapatkan, dan seberapa banyak like yang mereka dapat. Guna menarik reader agar menjadi follower di akunnya, author Wattpad melakukan berbagai hal antara lain dengan mencari cast yang menjadi roleplay cerita mereka dari public figure terkenal yang banyak digemari. Selain itu para author Wattpad juga membuat video, gambar, atau membubuhkan video klip lagu yang sesuai untuk cerita mereka. Biasanya, cerita yang dibubuhi video dan gambar akan lebih menarik reader. Author juga akan membuat cover yang menarik bagi novelnya. Tak jarang penulis meminta pendapat para reader untuk menentukan cover yang menarik dan sesuai untuk ceritanya.

Selain dari segi media pendukung, para reader Wattpad tertarik pada cerita bernuansa romance dan memuat adegan seks. Cerita-cerita yang ada di Wattpad memiliki gaya bahasa seperti sastra terjemahan. Setting dan nama tokoh yang digunakan pun berbau kebaratan. Jika pada tahun 2000-an dunia kesusastraan di Indonesia diramaikan dengan sastra popular chicklit dan teenlit, maka cerita di akun Wattpad memilki gaya yang hampir sama namun memuat adegan seks yang panas seperti pada sastra popular yang berkembang di tahun 1990-an. Guna menarik minat follower, maka para author Wattpad berlomba-lomba membuat cerita dengan adegan seks.

Banyak author yang menelan mentahmentah pemahaman ini bahwa adegan seks bukanlah bumbu semata melainkan inti yang harus ada dan mendominasi cerita. Mereka bahkan tidak memedulikan lagi alur dan konteks cerita. Yang mereka pentingkan hanyalah adegan seks yang panas. Beberapa novel Wattpad yang memuat adegan seks panas dan menjadikannya sebagai pokok cerita adalah novel Perempuan Kedua karya Feti Riana, My Arogan Princess karya Feti Riana, Virgin Chocolate is Mine karya Emerald, Temporary Lover karya CarmenLa Bohemian, Claimed by The Pirate karya CarmenLa Bohemian, dan Diet Juice karya Emerald.

Namun, ada pula beberapa penulis yang tetap berpegang teguh pada hakikat sastra yang semestinya bahwa novel yang baik adalah novel yang memilki konten cerita menarik dan bernilai. Adegan seks yang ada pada novel ini hanyalah sebagai sarana untuk menyampaikamn maksud dan nilai cerita. Penulis yang memegang prinsip ini biasanya menyisipkan pengetahuan, filosofi, dan kutipan-kutipan yang cerdas. Para follower-nya pun tentu adalah para reader yang memilki kriteria dan selera yang berbeda dengan jenis cerita yang dijelaskan di awal tadi. Beberapa novel Wattpad yang masuk dalam kriteria ini antara lain novel-novel yang ditulis oleh Arthemis14 dengan judul Bastard Prince, Claimed Me, Lost to Love, Hank Dover, dan The Game of Fate. Selain itu novel-novel karya Malashanti yang berjudul Unforgettable Chemistry, Heart Décor, Mirvala, dan Aldebaran. Ada juga My Bastard Prince karya Daasa.

\section{3. Komodifikasi Sastra Cyber Wattpad ke Sastra Cetak Melalui Penerbit Indie}

Ketenaran yang didapat oleh author kemudian memantik semangatnya untuk meningkatkan eksistensinya, yaitu dengan 
menerbitkan tulisannya dalam bentuk buku ber-ISBN yang bisa dijual dalam bentuk cetak, membuat video, mercandise, hingga sosial media yang dimainkan oleh roleplay cerita mereka.

Guna menjadikan cerita yang telah ditulis di akun Wattpad menjadi buku berISBN, maka penulis memerlukan bantuan penerbit. Kegiatan penerbit dapat dirangkum dengan tiga kata kerja: memilih, membuat (fabriquer), dan membagikan. Tiga kegiatan itu saling berkaitan. Masing-masing bergantung satu sama lain, saling memengaruhi, serta membentuk suatu siklus yang merupakan keseluruhan kegiatan penerbitan (Escarpit, 2005: 74). Kebanyakan penulis Wattpad memilik penerbit indie untuk menerbitkan karya mereka dengan berbagai pertimbangan. Saat ini, ditemui lebih dari 500 penulis Wattpad yang menerbitkan tulisannya melalui penerbit indie.

Pertimbangan author Wattpad memilih penerbit indie untuk menerbitkan karyanya antara lain karena penerbit indie tidak menerapkan sistem seleksi pada karya yang masuk. Penerbit indie juga akan mengizinkan penulisnya untuk tetap mencantumkan bagian-bagian cerita yang dikehendaki oleh penulisnya. Penulis novel Wattpad tidak rela menghilangkan bagianbagian cerita, terlebih adegan seks yang kemungkinan besar akan di-cut oleh penerbit mayor. Sistem kekeluargaan yang bersifat fleksibel yang diterapkan oleh penerbit indie selama sistem penerbitan naskah menjadi nilai plus yang memberikan keuntungan bagi penulis Wattpad.

Penerbitan karya Wattpad ini merupakan kegiatan industri budaya. Tujuan industri budaya yang dilakukan lebih pada tujuan komersil yang mengutamakan keuntungan finansial. Oleh karena itu novel Wattpad diproduksi berdasarkan permintaan pasar, hal yang menjadi salah satu ciri sastra populer. Hal ini seperti yang dikemukakan oleh Strinati (2009: 111) bahwa industri budaya menawarkan bentuk, bukannya substansi penyelesaian masalah, pemuasan semu atas kebutuhan palsu sebagai pengganti solusi riil berbagai persoalan nyata. Dalam hal ini industri budaya mengambil alih kesadaran massa.

Pertimbangan finansial menjadi faktor penting ketika memilih penerbit indie. Keuntungan finansial ini sangat berbeda dengan keuntungan yang akan mereka dapat jika menerbitkan naskah melalui penerbit mayor. Jika penerbit mayor hanya menawarkan royalti sebesar $10-15 \%$ dari harga buku, di penerbit indie penulis hanya membayar biaya cetak buku dan berhak menentukan sendiri besar harga dan royalti yang akan mereka dapatkan. Meskipun di awal penerbitan mereka harus membayar biaya penerbitan, namun tak sebanding dengan keuntungan yang mereka dapatkan ketika menjual bukunya.

Guna meningkatkan omset penjualan bukunya, penulis Wattpad memromosikan karyanya bahkan sebelum novel tersebut diterbitkan. Biasanya, para follower akan berlomba membeli karya yang telah terbit meskipun sebelumnya telah membaca versi elektronik. Hal ini semacam lifestyle para follower Wattpad. Jadi, bagi penulis Wattpad yang akunnya telah memiliki jumlah follower banyak tak khawatir bukunya tidak akan laku.

Di era kapitalisme, industri telah berevolusi menjadi penggerak gaya hidup massa. Bahkan sastra pun kini menjadi sebuah komoditas yang diperjualbelikan; sastra, sebagai komoditas, dijual dengan kemasan yang menarik dan bentuk yang indah serupa asesoris dan hiasan. Sedemikian rupa industri menyetir pola hidup massa sehingga muncul suatu gaya hidup. Orang yang tidak mengikuti gaya hidup, yang diciptakan secara masal oleh industri budaya, akan dianggap tidak wajar. Oleh karena itu, maka timbullah sebuah sikap fetisisme, yang diwujudkan secara nyata dengan adanya komoditas budaya yang dapat ditukar dengan alat tukar sah bernama uang. Uang sebagai alat tukar yang dinilai paling tepat kemudian menjadi tolok ukur kemampuan massa untuk membeli kehidupan sosialnya (Pratamanti, 2014: 20). 
Adorno (Strinati, 2009: 100) mengemukakan bahwa uang - harga komoditas atau barang termasuk budaya menjelaskan serta mendominasi hubungan sosial dalam masyarakat kapitalis. Hal ini juga merupakan pernyataan terkenal Karl Marx berkenaan dengan asal mula fetisisme komoditas. Selanjutnya dijelaskan pula bahwa Marx melakukan pemilahan antara asas pertukaran dan asas manfaat komoditas yang berputar-putar di dalam masyarakat kapitalis. Oleh karena itu, misteri wujud komoditas sebenarnya ada di dalam karakter sosial usaha manusia yang tampak sebagai suatu karakteristik objektif, suatu sifat alami sosial hasil kerja itu sendiri, dan sebagai akibatnya hubungan antar para produser dengan keseluruhan usaha mereka sendiri dihadirkan sebagai suatu hubungan sosial, tidak hanya terjadi di antara mereka sendiri, tapi juga di antara berbagai hasil kerja mereka (Strinati, 2009: 100).

Melalui penggambaran di atas, jelaslah bahwa sastra, bagian dari budaya, juga merupakan sebuah komoditas karena sastra telah masuk dalam dunia industri yang diproduksi dan dihasilkan secara besarbesaran serta ditujukan untuk dikonsumsi pasar. Karena industri budaya telah menjadi semacam gaya hidup massa, maka komoditas sastra telah ternoda oleh fetisisme komoditas yang dikuasai oleh media bernama uang.

Strinati (2009: 102) kemudian mengatakan bahwa yang khas pada komoditas-komoditas budaya adalah bahwa "asas manfaat secara licik mengambil alih fungsi asas manfaat. Sifat memuja (dari kata fetish yang membentuk istilah fetisisme) yang khas dari musik, misalnya, terletak pada quid pro quo (sesuatu yang diberikan atau dikembalikan sebagai balasan) ini." Fetisisme tersebut terlihat ketika seorang penikmat konser musik lebih bangga dan memuja harga tiket yang dibayarkan untuk dapat masuk ke gedung konser dan bukannya memuja pertunjukan musik itu sendiri. Begitu pula seorang remaja merasa bangga disanjung oleh teman-temannya karena mempunyai novel Harry Potter dengan seri yang lengkap.

Hal di atas sama halnya dengan para follower Wattpad yang bangga memiliki novel author favoritnya. Kepentingan membaca bukanlah kepentingan pokok karena sebenarnya mereka telah membaca dalam versi cetak. Bahkan follower rela mengeluarkan uang yang cenderung mahal untuk membeli sebuah buku meskipun mereka bisa membaca tanpa mengeluarkan sepeser uang pun melalui aplikasi Wattpad yang dapat diinstal di komputer atau smartphone.

Guna menunjang kegiatan komoditas buku Wattpad tersebut, selain dipromosikan melalui akun Wattpad, penulis juga memromosikan bukunya melalui media sosial baik media sosial pribadi maupun media sosial yang dijalankan oleh roleplay cerita mereka. Para penulis juga meminta bantuan para toko buku online untuk menjualkan bukunya. Penulis dan olshop buku biasanya membuat cover, video, dan gambar-gambar animasi untuk menarik minat konsumen. Tidak jarang pula penulis memberikan marchandise di setiap pembelian novelnya.

Dalam hal ini, maka jelaslah bahwa produksi karya sastra tidak hanya bertujuan untuk menciptakan sebuah karya yang dapat dinikmati oleh masyarakat pecinta karya sastra saja, namun kini karya sastra telah menjadi sebuah barang komoditas seperti halnya perlengkapan rumah tangga. Seperti yang dijelaskan oleh Pratamanti (2014: 37) bahwa karya sastra sama seperti benda komoditas yang lain, berorientasi pada keuntungan finansial. Di sini kapitalisme berperan penting. Karya sastra akan terus dikembangkan demi mendapat keuntungan finansial yang lebih banyak. Demi memeroleh keuntungan finansial tersebut, maka produsen karya sastra tidak berhenti memroduksi dan memasarkan karya sastra yang dihasilkannya. Proses produksi dan pemasaran karya sastra ini disertai dengan berbagai inovasi dan kreatifitas agar dapat menarik khalayak pembeli sebanyakbanyaknya. 


\section{Simpulan}

Dari serangkaian uraian di atas, dapat disimpulkan bahwa komodifikasi budaya merupakan salah satu isu kontemporer yang berkembang dan didukung dengan teknologi dan fasilitas maju pada zaman postmodern ini. Komodifikasi merupakan karya yang kemudian ditransformasikan menjadi bentuk komoditi sehingga menghasilkan barang produksi yang laku di pasaran. Kemudian di zaman yang serba modern dengan ekonomi global yang pesat ini, setiap kebudayaan bisa menghasilkan nilai jual yang akhirnya lahirlah istilah komodifikasi budaya.

Saat ini karya sastra telah merambah di berbagai wahana, sehingga wahana elektronik yang melibatkan jaringan internet dan dapat mencakup masyarakat luas yang dinilai sebagai wahana yang mutakhir. Dalam hal ini, sastra cyber yang dianggap akrab di masyarakat postmodern karena memenuhi segala aspek yang menjadi ciri khas masyarakat postmodern.

Wattpad pun kemudian muncul sebagai layanan situs yang memungkinkan pengguna internet untuk membaca atau mengirimkan karya sastra dalam bentuk cerita pendek, novel, puisi, atau karya sastra lain. Isu yang kemudian menarik yaitu beberapa penulis populer di Wattpad merasa tidak cukup puas dengan karya cyber-nya dan ingin melanjutkan karyanya ke dalam bentuk sastra cetak. Komodifikasi sastra cyber ke sastra cetak ini menjadi bentuk baru pola perkembangan dunia sastra di bidang produksi. Dengan melibatkan penerbit indie, komodifikasi budaya melalui Wattpad itu tidak menjadi hal yang mustahil. Adanya fenomena tersebut akan melahirkan persaingan kreatif antar pelaku sastra di era postmodern ini.

\section{Daftar Pustaka}

Endraswara, S. 2003. Metodologi Penelitian Sastra. Yogyakarta: Pustaka Jaya.

Escarpit, Robert. 2005. Sosiologi Sastra. (diindonesiakan oleh Ida Sundari
Hussein). Jakarta: Yayasan Obor Indonesia.

Farahiba, Ayyu Subbi. 10-11 Oktober 2016. Eksistensi Sastra Cyber Sebagai Media Komunikasi Antarbangsa. Seminar Nasional Sosiologi Sastra. Jakarta: Fakultas Ilmu Pengetahuan Budaya, Universitas Indonesia.

Hutcheon, Linda. 2006. A Theory of Adaption. London: Routledge.

Ibrahim, Idi Subandy dan Bachruddin Ali Akhmad. 2014. Komunikasi dan Komodifikasi. Jakarta: Yayasan Pustaka Obor Indonesia.

Kompas. 2002. Hantu sebagai Hiburan, 28 September, hal 13.

Mcllroy, Thad. 2017. An Authoritative Look at Book Publishing Startups In the United States. Canada: The Future of Publishing.

Pratamanti, Enggar Dhian. 2014. "Alih Wahana dan Komodifikasi Novel dan Komik 5cm." Tesis Magister Ilmu Susastra. Semarang: Universitas Diponegoro.

Strinati, Dominic. 2009. Popular Culture: Pengantar Menuju Teori Budaya Populer. Jogjakarta: Ar-Ruzz Media.

Turner, Bryan S. 1992. Max Weber: From History to Modernity. London: Routledge.

\section{Internet}

https://www.wattpad.com/story/105643256my-bastard-prince $\% \mathrm{E} 2 \% 9 \mathrm{C} \% 85$

https://www.wattpad.com/search/arthemis 14 https://www.wattpad.com/search/malashantii https://www.wattpad.com/search/kedaicerpen. 